\title{
Enhancing the Theory of Planned Behaviour by Incorporating Social Marketing Behavioural Enhancers: A First VS Second Order Confirmatory Factor Analysis Approach
}

\author{
Ayikwa, Lutete Christian, De Jager, Johan W. and Van Zyl, Dion \\ Tshwane University of Technology, Pretoria West, South Africa \\ chrisayikw@yahoo.fr, DeJagerJW@tut.ac.za,dionvanzyl@gmail.com
}

\begin{abstract}
This study investigated the need to extend the TPB model to SMBE variables as suggested by Ayikwa and De Jager (2017) in the quest to better understand sexual behavioural patterns using the Confirmatory Factor Analysis (CFA) approach. The main research question to be answered: "how the TPB and SMBE variables should be structured into a validated CFA model?" Data were carefully collected in South Africa's Gauteng Province using a disproportionate multi-stage stratified random sampling method to retain 607 respondents. The survey questionnaires distributed consisted of revisited pre-existing instruments. The data were then analysed by CFA model that followed Exploratory Factor Analysis (EFA) to determine the suitability of the sample size. Assessment of the second order extended TPB model confirmed that it is worthwhile to integrate SMBE variables while extending the TPB model in the context of HIV/AIDS related behaviours.
\end{abstract}

Keywords: Theory of Planned Behaviour, Social marketing, Health Behaviour change, Confirmatory Factor Analysis, Exploratory Factor Analysis and HIV/AIDS

\section{Introduction}

The Theory of Planned Behaviour (TPB), which is widely applied in numerous fields devoted to behavioural change, has been found the best in predicting both behaviour and intention of performing that behaviour when extended to additional variables through theoretical and empirical evidence (Conner \& Armitage, 1998). According to behavioural theory, the TPB itself is not less than an extension of the Theory of Reasoned Action (TRA) that identifies intentions as being the most immediate antecedents of any voluntarily performed behaviour (Kiriakidis, 2015). The original TRA comported two variables assuming to capture behavioural predictors that are attitudes (ATT) and subjective norms (SN), which later were added to perceived behavioural control (PBC). This refers to the acquired experience from the past regarding the performance of a behaviour and obstacles preventing its occurrence to form the TPB (Tao \& Fan, 2017). Thus, the extension of pre-existing models to one or more new components is common in the attempt to better understand social phenomena and behaviour occurring within a society under specific conditions in order to effect behavioural change. This study tested the theoretical framework proposed by Ayikwa and De Jager (2017) who proposed incorporating the SMBE alongside the traditional TPB components. The investigation consisted of assessing if the theoretical extended TPB model has a good fit with the empirically manifested structural model in order to validate the inclusion of the SMBE. A comparison between a first and second order Confirmatory Factor Analysis (CFA) approaches is made to identify the best approach to be used in a quest for a valid model.

\section{Literature Review}

The TPB offers a parsimonious framework that helps in determining the direct antecedents of a behaviour establishing the cause-effect relationships between predictors and behaviour as well as the intention to perform that behaviour (Ajzen \& Fishbein, 1980). It also enables detailed and in-depth analysis of the specific beliefs that act as a lever of behaviour and intention to perform that behaviour (Godin \& Kok, 1996). The TPB variables widely applied in behavioural fields to understand the prediction of specific individuals' behaviour towards an object, group of objects and situation are often related to the issue of attitude's unidimensionality (Kiriakidis, 2015). Attitude is defined by Fishbein (1967, p. 389) as "a learned predisposition to respond to an object or class of objects in a consistently favourable or unfavourable way." This newly developed perspective in the conceptualisation and definition of attitude stressed the view that the overall propensity to adhere to a specific sexual behaviour, or not to, is the same among individuals, while such individuals may express a different degree of acceptance and rejection towards adhesion to that sexual behaviour (Fishbein, 1967).

This unidimensionality has been indexed as the main problem for the failure to accurately predict individuals' sexual behaviour. Furthermore, PBC, which is assumed to predict behaviour both directly and indirectly 
through intention, is often influenced by internal and external factors that enable the occurrence of sexual behaviour under complete volitional control (Ajzen, 1985). Importantly, Tao and Fan (2017) argue that the relationships between the TPB's ATT, SN and PBC are not necessarily significant, and are affected by uncontrollable factors such as human behavioural beliefs. Thus, the inclusion of additional components as suggested in the context of this study find justification in the quest for designing a comprehensible framework of what may explain individuals' sexual behaviours with regard to the struggle against the spreading of the HIV virus. The human immunodeficiency virus (HIV) that has its roots in the DR Congo's Central Africa (Khonde, 2006) has since spread worldwide, burdening most the continent it originates from, and plaguing almost all the sectors of life (Luboobi \& Mugisha, 2005). In the absence of a cure for acquired immunodeficiency syndrome (AIDS), researchers have pointed out the need to promote the well-known "ABC" behaviours to slow the propagation of the virus (Ayikwa, 2013). It is therefore believed that abstinence from sex, being faithful to one partner and condom use are key sexual behaviours in tackling the epidemic to achieve an HIV/AIDS free generation.

In order to change individual's sexual behaviour towards the socially marketed "ABC" favourably, tailored campaigns are engineered to equip individuals with adequate knowledge regarding the meaning of HIV/AIDS, modes of acquisition of the virus and methods of prevention against getting infected (Agarwal \& De Araujo, 2012). Indeed, the raising of HIV/AIDS awareness among the population addresses the numerous misconceptions, beliefs and customs inked within societies and communities which pave ways for risky sexual behaviour as well as discrimination and stigmatisation of persons living with HIV/AIDS (Ayikwa \& De Jager, 2015). Hence, the efficient use of communication channels and strategies often employed by marketers is crucial in propagating the much-needed HIV/AIDS information as well as the implementation of effective distribution strategies to make condoms available for everyone. These efforts to increase individuals' HIV/AIDS level of knowledge, exposure to HIV/AIDS information and accessibility to condoms, made borrowing commercial marketing principles, techniques and strategies constitute what this study named Social Marketing Behavioural Enhancers (SMBE). The SMBE are therefore believed to contribute substantially alongside the TPB traditional components to affect individuals' sexual behaviours and intention to perform these behaviours.

Figure 1: First Order Latent Variables Extended TPB Model

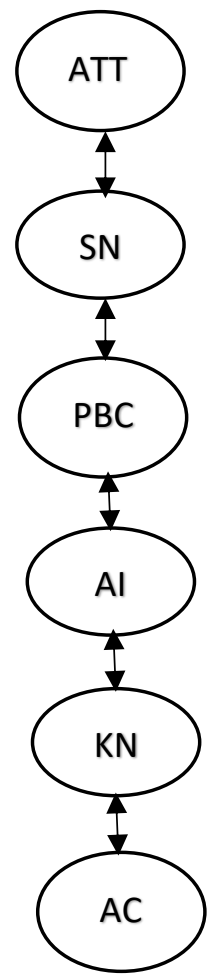

Figure 2: Second Order Latent Variables Extended TPB Model

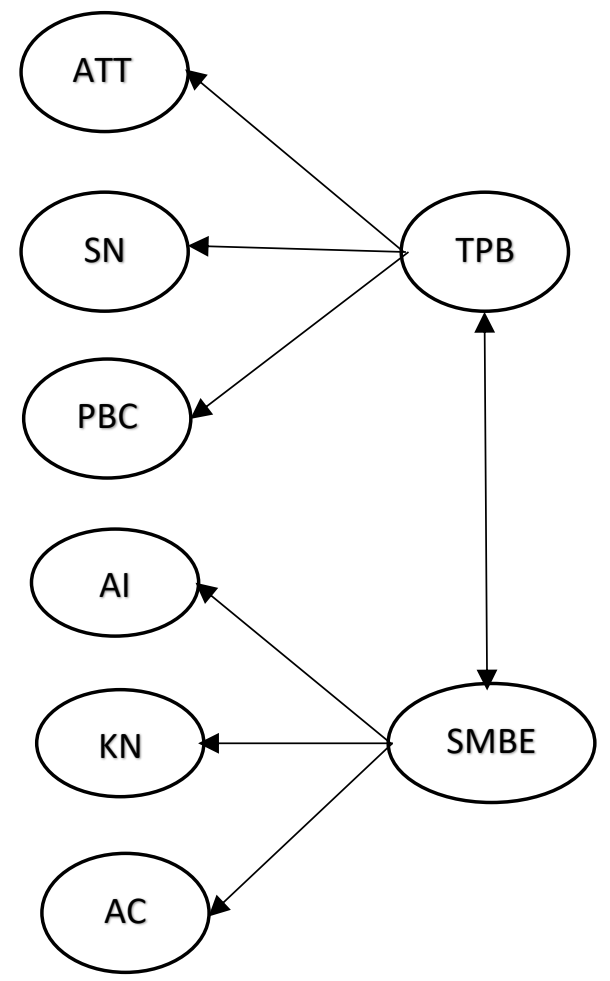


As noted in the Introduction, the aim of the study was to see if the extension of TPB to SMBE variables could best fit the data to support their inclusion using a CFA. Two approaches have been adopted, with the first considering both TPB and SMBE variables as first-order latent variables of their underlying dimensions. The second used a second-order latent variables approach, making the TPB and SMBE latent variables of their respective underlying first-order latent variable dimensions. Figures 1 and 2 above illustrate both approaches.

\section{Research Method}

Instrumentation: This study adopted a questionnaire instrument comprising three sections to collect data from a randomly selected sample of Gauteng's inhabitants. It was developed on the basis of the framework proposed on the procedures for measuring complex multidimensional research variables (Lin, 2013). Questions and scales used in several other studies devoted to the HIV/AIDS epidemic, with particular emphasis on those conducted in Sub-Saharan Africa, and more specifically the Southern Africa region such as Sacolo et al. (2013), Ugwu (2012), Mathews et al. (2009), Mayhew et al. (2009), Tameru et al. (2012), Imaledo (2012) and Selikow (2004), were considered to influence this study's instrument. The first section captured basic information describing the respondents' profile such as gender, age, level of education, occupation, marital and socioeconomic status. The second section consisted of a set of TPB-related questions measuring attitude (ATT), subjective norms (SN) and perceived behavioural control (PBC) constructs by five-point Likert-type scale from 1 indicating "strongly disagree" to 5 indicating "strongly agree." ATT was measured through 42 questions, SN 38 questions and PBC were measured by 16 questions. All three traditional TPB constructs were measured with regards to the promoted "ABC" behaviours. The third section of the instrument was related to the SMBE constructs.

The responses to the questions regarding accessibility to HIV/AIDS information (AI) and HIV/AIDS knowledge (KN) constructs consisted of a categorical yes/no response. The AI construct was measured by 17 questions enumerating the media that have provided respondents with HIV/AIDS information or advertisement as they recalled. HIV/AIDS knowledge related to the general meaning, signs and symptoms of the disease, and mode of transmission. Methods to prevent the acquisition of HIV virus were assessed by asking 44 questions. On the contrary, the accessibility to condoms (AC) construct which measured the easiness for respondents to get condoms through formal and/or informal outlets consisted of a three-point Likert-type scale from 1 indicating "not easy" to 3 indicating "very easy." Respondents' easiness to get condoms was measured by 6 questions. The overall validity and reliability analysis of the questionnaire demonstrate that items used in this study contributed meaningfully to their respective scales with, an average item-total correlations $>.2$ indicating a good internal consistency which turned out to be reliable (Cronbach alpha $>.60$ ) as shown in Table 1.

Table 1: Validity and Reliability Analysis on Constructed Scales of the Questionnaire

\begin{tabular}{llll}
\hline Construct & Number of items & Average item-total correlations & Cronbach Alpha \\
\hline ATT & 42 & .46 & .93 \\
SN & 28 & .40 & .86 \\
PBC & 12 & .56 & .87 \\
AI & 17 & .42 & .82 \\
AC & 6 & .45 & .72 \\
KN & 44 & .22 & .75
\end{tabular}

$\mathrm{ATT}=$ Attitude; $\mathrm{SN}=$ Subjective norms; $\mathrm{PBC}=$ Perceived behavioural control; AI $=$ Accessibility to HIV/AIDS information; $\mathrm{AC}=$ Accessibility to condoms; KN = HIV/AIDS level of knowledge.

Sampling and Data Collection: The questionnaire of the study was administered by trained research assistants involved in data collection. They were requested to approach respondents at random, preferably in their area of residence. The criteria of eligibility included being a South African citizen, living in one of the Gauteng Province's cities, and aged eighteen years and above. Only, participants that consented to answer the study questionnaire were invited to participate anonymously and confidentially. The present study used a disproportionate multi-stage stratified random sampling method to retain 607 respondents out of an estimated 13.5 million Gauteng Province's inhabitants (Statistics South Africa). 
The sampling procedures consisted, first, in dividing the Gauteng Province into metropolitan and district municipalities. Secondly, the metropolitan and district municipalities were divided respectively by three and two in reflection of the administrative distribution of the province. The three metropolitan municipalities are Ekurhuleni/East Rand-Germiston, Johannesburg and Tshwane-Pretoria. The two district municipalities include Sedibeng and West Rand. Thirdly, the list of cities and towns within each municipality served as a sampling frame from which cities and towns that constituted the study's research fields were randomly selected. Although the numbers of cities and/or towns were determined according to each municipality's population in the province's population distribution, participants, who are the study's unit of analysis, were chosen randomly. However, the researcher tried to determining selected municipalities' sample sizes to reflect on their respective population distribution's weight to obtain a realistic representative distribution of the Gauteng Province's population. Thus, Alexandra, Boksburg, Centurion, KwaThema, Mamelodi, Randburg, Sandton, Sebokeng, Soshanguve, Soweto, Tembisa and Wedela were the selected cities and/or towns.

\section{Empirical Analysis and Results}

Descriptive Statistics: The demographic profile of the 607 respondents as summarised in Table 2 indicates that the sample mostly comprised female participants (51.1\%), and young adults aged 25-34 (44.3\%) were the major age group. Educationally, most of the respondents achieved standard 10/grade 12 (38.4\%). Respondents are in majority full-time employees (39.4\%). The commonly reported marital status by respondents was "single" (62.8\%), and most of them are classified as impoverished with regards to their socioeconomic status $(25.5 \%)$.

Table 2: The Demographic Profile of the Respondents ( $\mathrm{N}=607)$

\begin{tabular}{lll}
\hline & Frequency & Percentage (\%) \\
\hline Gender & 310 & \\
Female & 297 & 41.1 \\
Male & & \\
Age & 152 & 25.0 \\
$\geq 18-24$ & 269 & 44.3 \\
$25-34$ & 186 & 30.6 \\
35+ & & \\
Level of education & 1 & .2 \\
No schooling & 33 & 5.4 \\
Postgraduate degree & 2 & .3 \\
Some Primary schooling & 233 & 38.4 \\
Standard 10/Grade 12 & 2 & .3 \\
Standard 5/Grade 7 & 6 & 1.0 \\
Standard 7/Grade 9 & 19 & 3.1 \\
Standard 8/Grade 10 & 33 & 5.4 \\
Standard 9/Grade 11 & 122 & 20.1 \\
Tertiary certificate & 102 & 16.8 \\
Tertiary diploma & 54 & 8.9 \\
Undergraduate degree & & \\
Occupation & 48 & 7.9 \\
Do piece jobs for money & 239 & 39.4 \\
Employed full time & 91 & 15.0 \\
Employed part time & 68 & 11.2 \\
Full-time student/learner & 27 & 4.4 \\
Other & 134 & 22.1 \\
Unemployed & & \\
& 17 & 2.8 \\
Marital status & 62 & 10.2 \\
Divorced/Widow[er] & 143 & 23.6 \\
Living together & & \\
Married & & \\
\hline
\end{tabular}




\begin{tabular}{lll} 
Other & 4 & .7 \\
Single & 381 & 62.8 \\
Socioeconomic status & & \\
Impoverished & 155 & 25.5 \\
Almost impoverished & 100 & 16.5 \\
Medium & 120 & 19.8 \\
Almost wealthy & 139 & 22.9 \\
Wealthy & 93 & 15.3 \\
\hline
\end{tabular}

Exploratory Factor Analysis: The data collected from the research ground by means of participants' response to the questionnaire were subjected to SPSS version 23.0 as the first stage of analysis to identify the items component loading with exploratory factor analysis (EFA). The reason behind running an EFA was to identify the variables structure of the questions explaining the specified underlying dimensions of each construct considered in the present study (Belkin, 2009). Principle Component Analysis extraction method and varimax rotation were employed to generate the uncorrelated extracted component with an eigenvalue greater than 1.0 with the application of SPSS version 23.0. The standardized factor loading and Cronbach's alpha were used under the EFA to determine the underlying questions for the extracted component structure of each variable. According to Hair, Babin, Black and Anderson (2010) the accepted threshold valued of standardized factor loading is .5, but this study employed a .3 cut-off as in Shyu, Li and Tang (2013). Although it depends on what is being measured, Nunnally and Bernstein (2010) suggest that a value greater than .7 is regarded as a satisfactory level of internal consistency reliability while Cohen, Manion and Morrison (2011) point out a value of .5 as acceptable for broad group measures like the present study.

Remarkably, the Cronbach alpha of all the constructs were adequate scoring each a value above .6. Furthermore, the data suitability for factor analysis and the sample adequacy were determined through Kaiser-Meyer-Olkin (KMO) and Bartlett's Test for Sphericity. The KMO coefficients for all constructs were higher than the acceptable level of .5 and their Bartlett's Test for Sphericity values was significant at $\mathrm{p}<.001$ providing evidence that the study's sample size (607) was appropriate for carrying out EFA. Following the EFA that demonstrated convergent validity and reliability of the study's instrument, constructs have been reorganised with regard to their new underlying components (grouped questions). ATT was best explained by six new components, as was SN. PBC was best explained by three new components, as was AI. AC, on the other hand, was best explained by two new components, while KN was explained by 10 new components. This study used Amos software tools version 23.0 to test the adequacy of the study's extended TPB measurement models for both first and second order latent variables approaches by means of the Maximum likelihood (ML) estimation method.

Confirmatory Factor Analysis: The purpose of conducting a CFA is to determine the consistency of the various composites parameters such as factor loadings, factor variances, covariance, indicator error variances and error covariance with an observed set of data (Kline, 2010). ML provides this study with the goodness-offit indices such as the chi-square (CMIN), degree of freedom (DF), Bentler-Bonett normed fit index (NFI), relative fit index (RFI), non-normed fit index (TLI), comparative fit index (CFI), root-mean-square error of approximation (RMSEA) and the standardised root-mean-square residual (SRMR) to assess the models under investigation. The fit statistics threshold for CFA is shown in Table 3. On the other hand, convergent validity and internal consistency were measured by means of Average Variance Extracted (AVE) and Composite Reliability (CR). A threshold is often set at $\geq .5$ for the AVE as well as the standard factor loading for convergent validity but lesser values are acceptable to proceed with the overall model fit test if offending estimate does not occur (Huang, 2007). Offending estimate is manifested by negative error covariance and/or standardized regression coefficient close to 1 (Shyu, Li, \& Tang, 2013). Although a $\geq .7$ benchmark is generally used to consider the adequacy of the CR, a renowned researcher in 1978, Nunally, suggested a lesser value of $\geq .5$ as acceptable to ascertain reliability (Shyu, Li, \& Tang, 2013). 
Table 3: Reported Fit Statistics for CFA and SEM

\begin{tabular}{lll}
\hline Measure & Name & Cut-off for good fit \\
\hline CMIN/DF & Chi square/Degree of freedom & $\leq 5.0$ to 2.0 \\
NFI & Bentler-Bonett normed fit index & $\geq .9$ to 1 \\
RFI & Relative fit index & $>.9$ \\
TLI & Non-normed fit index & $>.9$ (sometimes $>.8)$ \\
CFI & Comparative fit index & $\geq .9$ to 1 \\
RMSEA & Root-mean-square error of approximation & $\leq .8$ \\
SRMR & Standardised root-mean-square residual & $\leq .8$ \\
\hline
\end{tabular}

As per the required procedures, each construct's measurement model was firstly assessed individually (MacKenzie, Podsakoff, \& Podsakoff, 2011). Estimation of the TPB-related constructs demonstrated that the six component variable model of ATT and SN dimension suggested a poor fitting model in the initial estimate. The CMIN/DF, RMSEA and SRMR were above the permissible level while GFI, NFI, CFI, TLI, AVE and CR were below the acceptable level. Hence, the component that showed factor loading $<.4$ was removed for being the major cause of poor fitting. The resulting model was found to be a good fitting model with recommended indices as illustrated in Figures 3 and 4. On the contrary, the three component variable model of PBC dimension suggested a perfect fitting model in the initial estimate as illustrated in Figure 5. All the paths shown in the final models of TPB-related constructs were significant as critical ratios were above 1.96.

Estimation of the SMBE-related constructs showed that the three component variable model of AI dimension and the two-component variable model of AC dimension suggested a perfect fitting model in the initial estimate as illustrated in Figure $\mathbf{6}$ and 7. However, an attempt was made to remove channels 3 which showed a factor loading <.4 from AI measurement model but it led the model to be unidentified. Thus, the decision was made to keep the component channels 3 in the model as offending estimate did not occur. On the contrary, the 10 component variable model of KN dimension suggested a poor fitting model in the initial estimate. The CMIN/DF, RMSEA and SRMR were above the permissible level while GFI, NFI, CFI, TLI, AVE and CR were below the acceptable level. Hence, the component that showed factor loading <.4 was removed for being the major cause of poor fitting. The resulting model was found to be a good fitting model with recommended indices as illustrated in Figures 8. All the paths shown in the final models of SMBE-related constructs were significant as critical ratios were above 1.96 .

Figure 3: Attitude Measurement Model

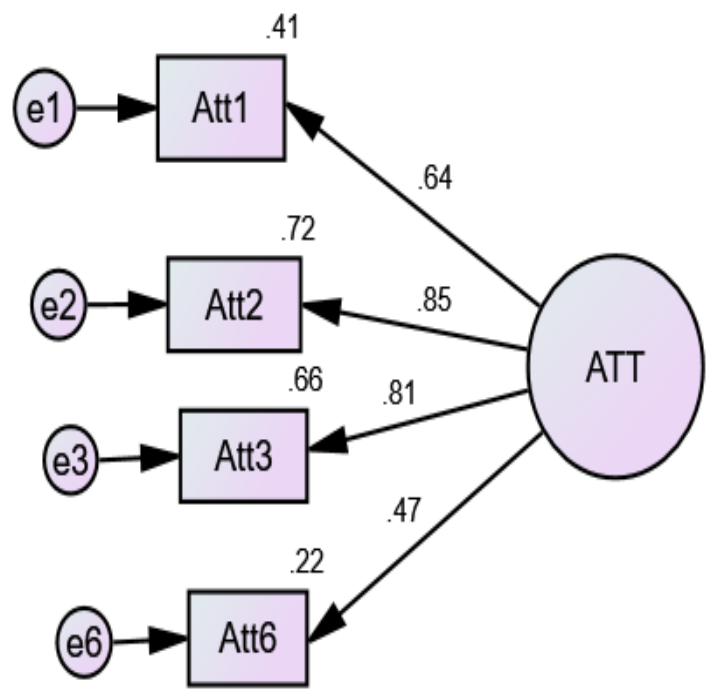

$\mathrm{CMIN}=9.98 ; \mathrm{DF}=2 ; \mathrm{CMIN} / \mathrm{DF}=4.99 ; \mathrm{p}=.01 ; \mathrm{GFI}$ $=.99 ; \mathrm{NFI}=.99 ; \mathrm{CFI}=.99 ; \mathrm{TLI}=.97 ; \mathrm{RMSEA}=.08 ;$ $\mathrm{SRMR}=.02 ; \mathrm{AVE}=.502 ; \mathrm{CR}=.794$
Figure 4: Subjective Norms Measurement Model

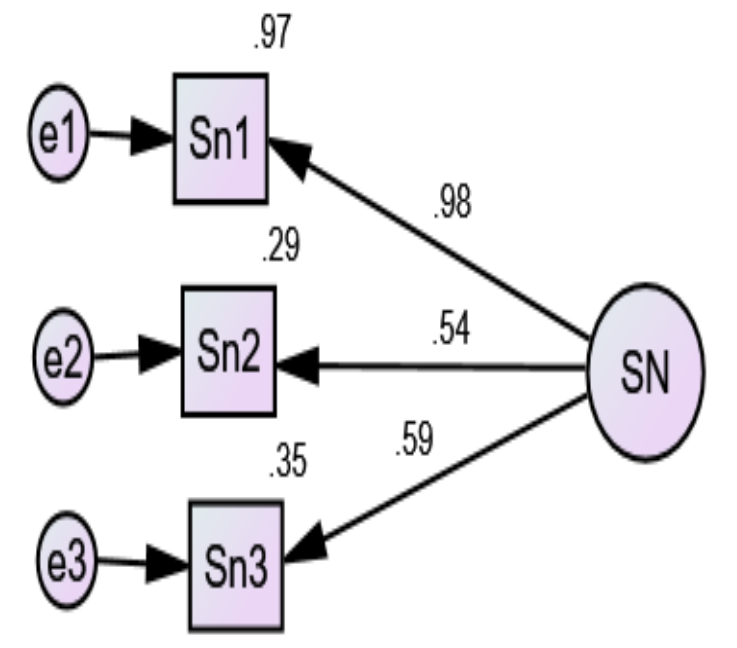

$\mathrm{CMIN}=.00 ; \mathrm{DF}=0 ; \mathrm{CMIN} / \mathrm{DF}=-; \mathrm{p}=-; \mathrm{GFI}=1.00 ; \mathrm{NFI}$ $=1.00 ; \mathrm{CFI}=1.00 ; \mathrm{TLI}=-;$ RMSEA $=-;$ SRMR $=.00$; $\mathrm{AVE}=.533 ; \mathrm{CR}=.761$ 


\section{Figure 5: Perceived Behavioural Control Figure 6: Accessibility to HIV/AIDS Information} Measurement Model

Measurement Model
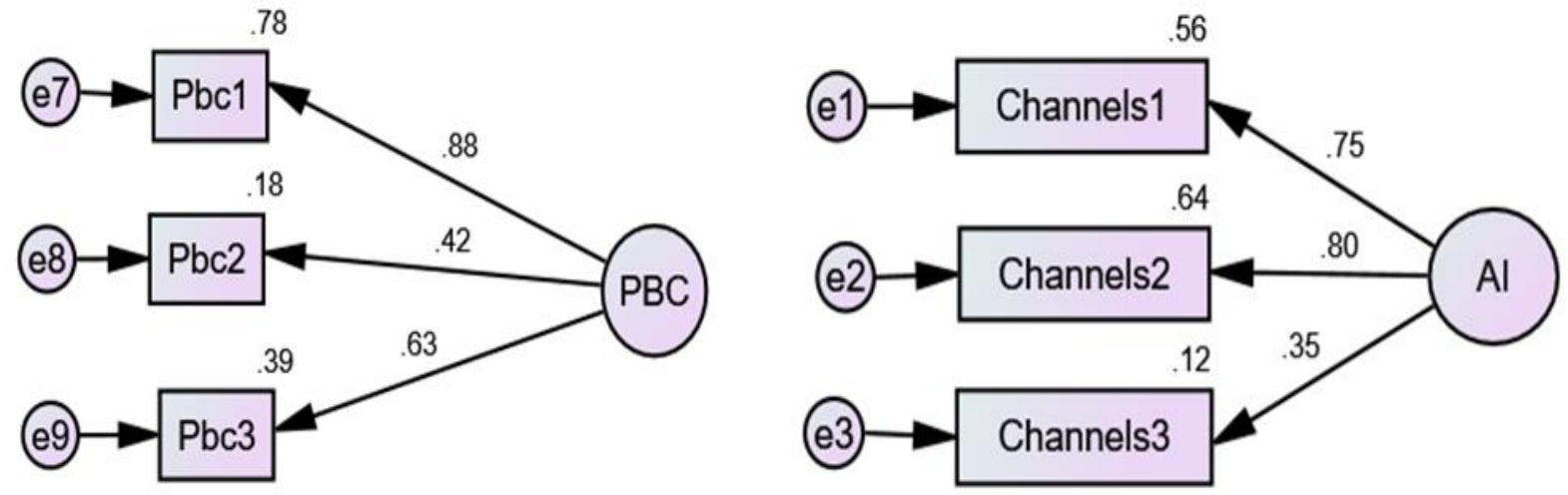

$\mathrm{CMIN}=.00 ; \mathrm{DF}=0 ; \mathrm{CMIN} / \mathrm{DF}=-; \mathrm{p}=-; \mathrm{GFI}=1.00$; $\mathrm{NFI}=1.00 ; \mathrm{CFI}=1.00 ; \mathrm{TLI}=-; \mathrm{RMSEA}=-; \mathrm{SRMR}=$ $.00 ; \mathrm{AVE}=.449 ; \mathrm{CR}=.693$

$\mathrm{CMIN}=.00 ; \mathrm{DF}=.00 ; \mathrm{CMIN} / \mathrm{DF}=-; \mathrm{p}=-; \mathrm{GFI}=1.00 ;$

$\mathrm{NFI}=1.00 ; \mathrm{CFI}=1.00 ; \mathrm{TLI}=-; \mathrm{RMSEA}=-; \mathrm{SRMR}=.00$;

$\mathrm{AVE}=.442 ; \mathrm{CR}=.683$

\section{Figure 7: Accessibility to Condoms Figure 8: HIV/AIDS knowledge Measurement Measurement Model \\ Model}
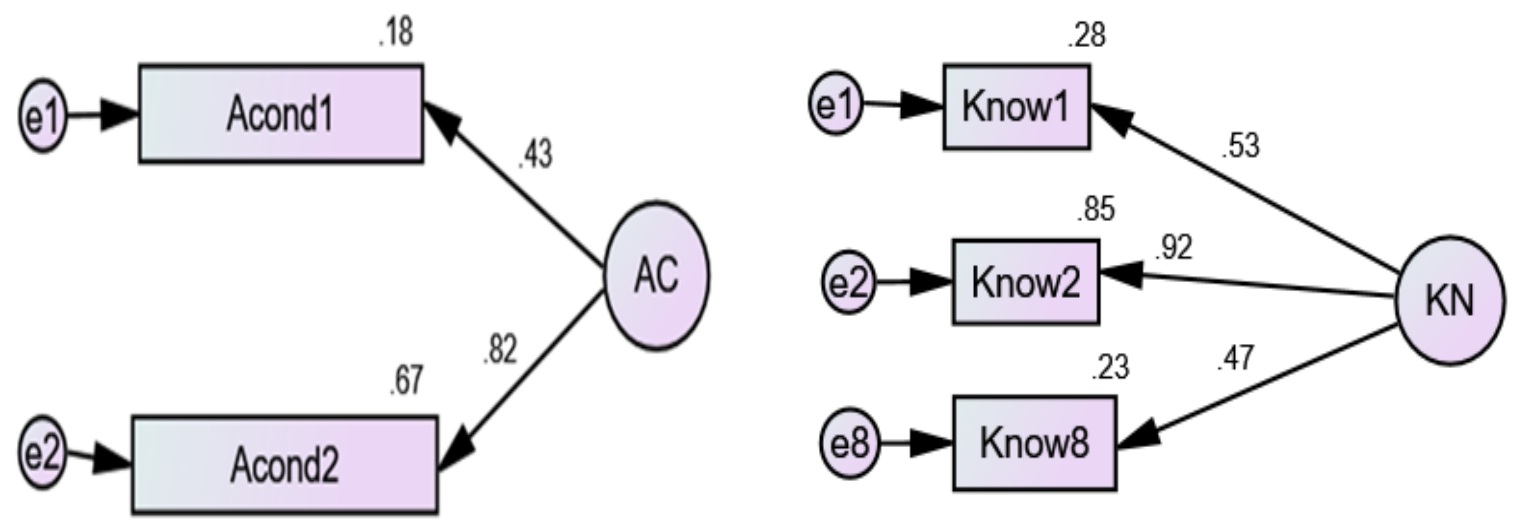

$\mathrm{CMIN}=.00 ; \mathrm{DF}=.00 ; \mathrm{CMIN} / \mathrm{DF}=-; \mathrm{p}=-; \mathrm{GFI}=$ 1.00; NFI $=1.00 ;$ CFI $=1.00 ;$ TLI $=-;$ RMSEA $=-$; $\mathrm{SRMR}=.00 ; \mathrm{AVE}=.429 ; \mathrm{CR}=.578$

$\mathrm{CMIN}=.00 ; \mathrm{DF}=0 ; \mathrm{CMIN} / \mathrm{DF}=-; \mathrm{p}=-; \mathrm{GFI}=1.00 ; \mathrm{NFI}$ $=1.00 ; \mathrm{CFI}=1.00 ; \mathrm{TLI}=-; \mathrm{RMSEA}=-; \mathrm{SRMR}=.00$; $\mathrm{AVE}=.449 ; \mathrm{CR}=.691$

Extended TPB Measurement Model: First Order Latent Variables Approach: The first approach adopted by this study consisted in merging all the construct's measurement models to see if the new model fits the data to confirm the utility, and justify the extension of the traditional TPB components by the SMBE variables. The initial estimate suggested a poor fitting model with the CMIN/DF, RMSEA and SRMR indexes above the permissible level while GFI, NFI, CFI and TLI were below the acceptable level. On the contrary, both the AVE and CR met the required level. Investigation based on the modification indices resulted in allowing some measurement errors to correlate as illustrated in Figure 10, enabling the study to achieve good fitting indices. The practice of correlating errors has raised concern in the scientific community as it may lead the researcher to omit relevant variables while achieving good fit statistics, obtain significant correlation due to sampling errors and/or bias the parameter estimates of both measurement and structural model (Hermida, 2015). However, consideration of the practice of allowing errors to correlate is justifiable when driven by theory rather than by the empirical purposes to fit the data, which was the case in this study as it can be assumed that those errors share some variance due to the narrowness of the link between these variables from the common sense of respondents' understanding. All the paths shown in the final model are significant as critical ratios were above 1.96 . 
Although the CFA results obtained from the first order latent variables approach was the best fit of the data, high correlations between TPB constructs (above the .85 permissible level) indicated that they are not statistically distinguishable or they meant, in essence, the same thing to the respondents. Therefore, it was ascertained that the TPB constructs did not show discriminant validity following the Fornell and Larcker criterion (Ab Hamid, Sami, \& Mohamed Sidek, 2017) with their squared-root of AVE being below their respective correlations as illustrated in Table 4. In this case, the researcher was left with two options consisting in either retaining only one construct or combining them. Choosing one construct over the others would mean that the retained construct is more useful, which contradicts the TPB theory; hence, the second option was adopted.

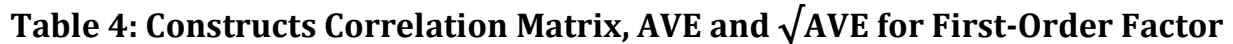

\begin{tabular}{llllllll}
\hline & AVE & ATT & SN & PBC & AI & AC & KN \\
\hline ATT & .502 & .709 & & & & & \\
SN & .533 & $.764^{* *}$ & .730 & & & & \\
PBC & .449 & $.786^{* *}$ & $.740^{* *}$ & .670 & & & \\
AI & .442 & .035 & .062 & $.096^{*}$ & .665 & .655 & \\
AC & .429 & .078 & .077 & .039 & .023 & $.083^{*}$ & $\mathbf{. 6 7 0}$ \\
KN & .449 & $.123^{*}$ & $.115^{* *}$ & $.110^{*}$ & $.086^{*}$ & $.083^{*}$
\end{tabular}

**. Correlation is significant at the 0.01 level (2-tailed); *. Correlation is significant at the 0.05 level (2-tailed); Square-root of AVE is in bold on the diagonal

Figure 9: Confirmatory Model for Extended TPB Dimension/ $1^{\text {st }}$ Order Latent Variable Approach

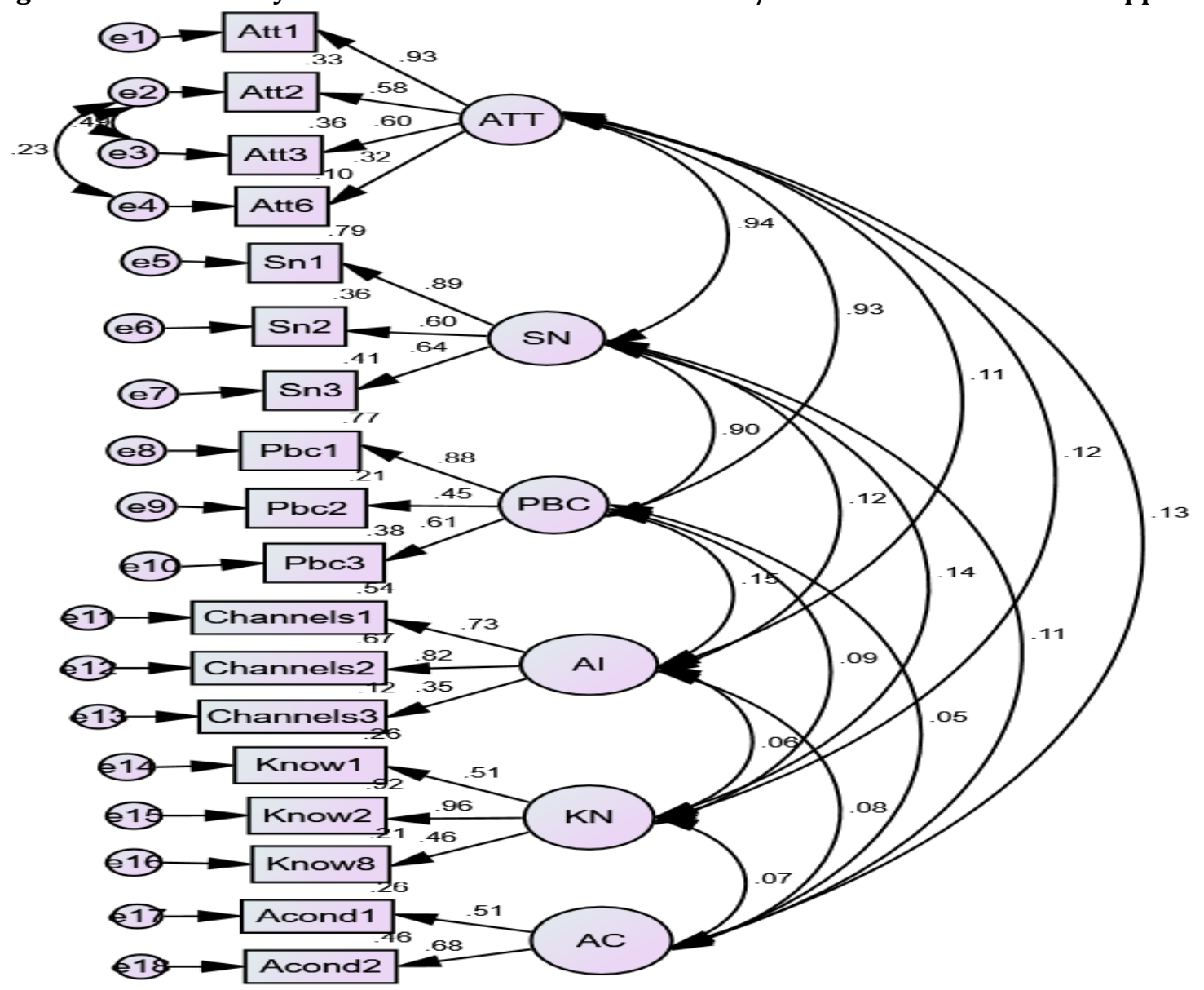

$\mathrm{CMIN}=433.59 ; \mathrm{DF}=118 ; \mathrm{CMIN} / \mathrm{DF}=3.67 ; p=.00 ; \mathrm{GFI}=.93 ; \mathrm{NFI}=.92 ; \mathrm{CFI}=.90 ; \mathrm{TLI}=.90 ; \mathrm{RMSEA}=.07 ;$

$\mathrm{SRMR}=.052 ; \mathrm{AVE}=.445 ; \mathrm{CR}=.930$ 
Extended TPB Measurement Model: Second Order Latent Variables Approach: On second thought, this study intended to examine whether the proposed extended TPB model could fit the data without transgressing constructs' convergent and discriminant validity if the first order latent variables represented by ATT, SN, PBC, AI, AC and KN were reflective latent variables of the TPB and SMBE second-order latent variables respectively. First, the three measurement models of the underlying dimensions of the traditional TPB have been integrated together in order to assess the measurement model of "TPB" dimension. The initial estimate suggested a poor fitting model with the CMIN/DF, RMSEA and SRMR indexes above the permissible level while GFI, NFI, CFI and TLI were below the acceptable level. On the contrary, both the AVE and CR met the required level. Investigation based on the modification indices resulted in allowing some measurement errors to correlate as illustrated in Figure 10, enabling the study to achieve good fitting indices. Furthermore, errors are allowed to correlate only for observed variables within the same construct and in the case of the present study, ATT, SN and PBC were considered as being within the same second-order TPB construct. All the paths shown in the final model are significant as critical ratios were above 1.96 .

Figure 10: Measurement Model for TPB Dimension

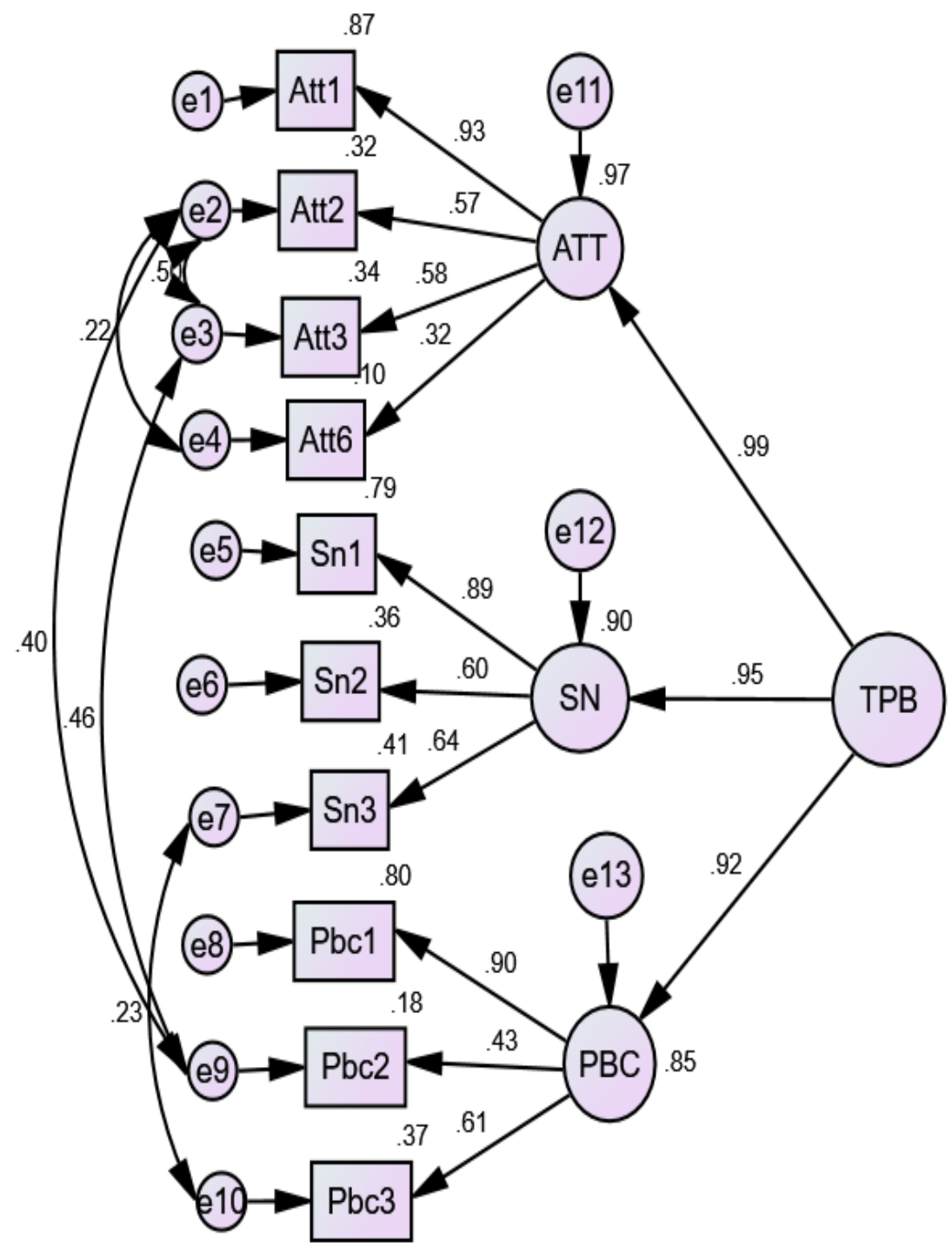

$\mathrm{CMIN}=133.83 ; \mathrm{DF}=27 ; \mathrm{CMIN} / \mathrm{DF}=4.96 ; p=.00 ; \mathrm{GFI}=.96 ; \mathrm{NFI}=.96 ; \mathrm{CFI}=.97 ; \mathrm{TLI}=.94 ; \mathrm{RMSEA}=$ $.08 ; \mathrm{SRMR}=.04 ; \mathrm{AVE}=.910 ; \mathrm{CR}=.968$ 
Secondly, the three measurement models of the underlying dimensions of the SMBE have been integrated together in order to assess the measurement model of "SMBE" dimension. The initial estimate suggested a good fitting model as illustrated in Figure 11 with all the parameters meeting the required level. However, AVE and CR as shown in Figure 11 showed a lack of convergent validity for SMBE as a second-order latent variable but no offending of estimate occurred. As suggested by Kline (2010) and Schumacker and Lomax (2012), the only combination of factor loadings $\leq .5$ and non-significant paths are inadmissible even when creating a second-order latent variable. Although factor loadings are poor, all the paths shown in the final model are significant as critical ratios were above 1.96. Therefore, for the purpose of processing with the second-order extended TPB model, the SMBE measurement model was accepted as such.

Figure 11: Measurement Model for SMBE Dimension

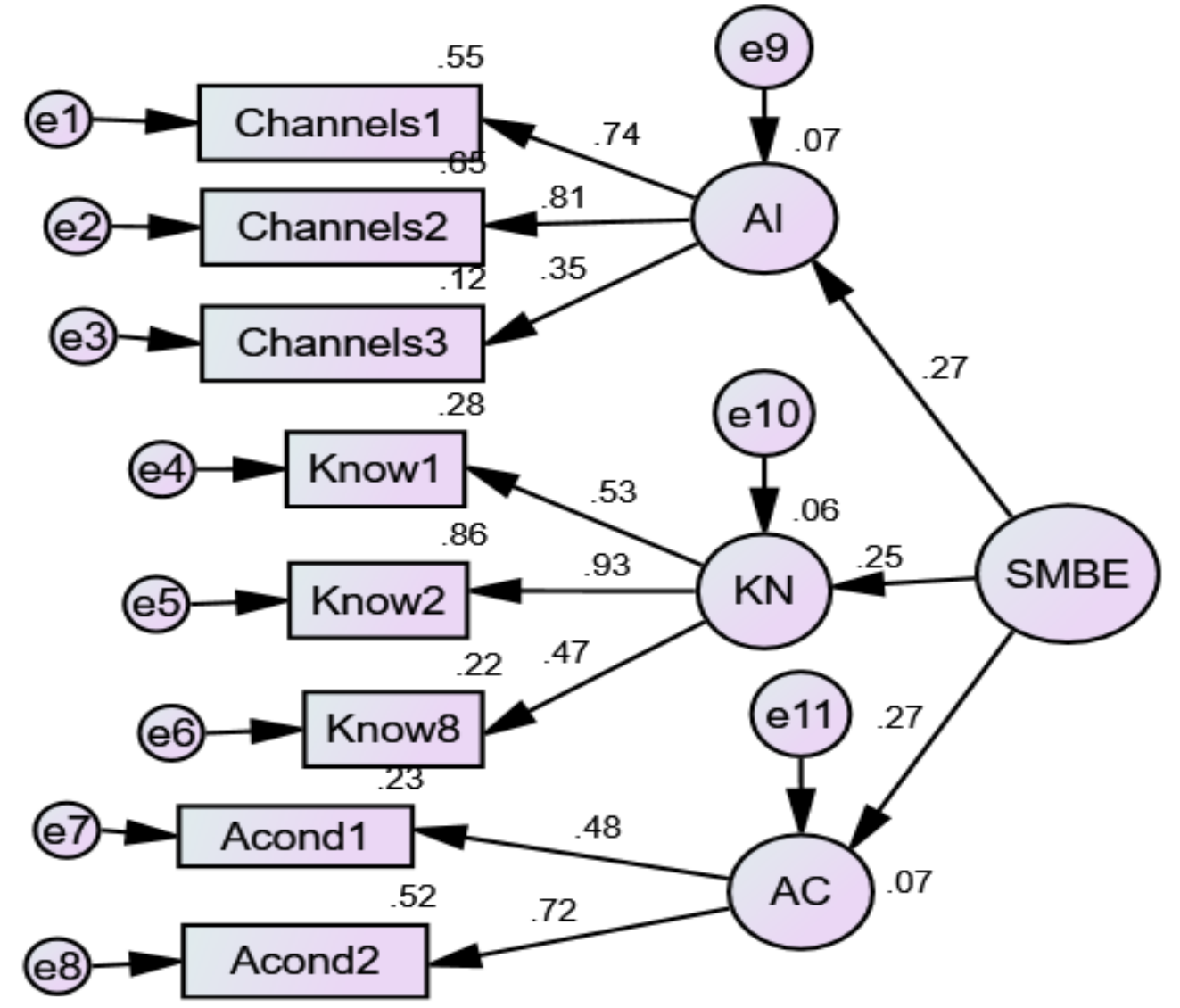

$\mathrm{CMIN}=21.49 ; \mathrm{DF}=18 ; \mathrm{CMIN} / \mathrm{DF}=1.19 ; \mathrm{p}=.26 ; \mathrm{GFI}=.99 ; \mathrm{NFI}=.97 ; \mathrm{CFI}=.995 ; \mathrm{TLI}=.99 ; \mathrm{RMSEA}=.02 ;$

$\mathrm{SRMR}=.03 ; \mathrm{AVE}=.058 ; \mathrm{CR}=.155$

Following the assessments of both TPB and SMBE measurement models, the TPB measurement model was integrated with the SMBE measurement model to obtain the measurement model of "extended TPB" dimension in the perspective of a second-order latent variable approach. The initial estimate suggested a good fitting model as illustrated in Figure 12 with all the parameters meeting the required level. Despite the CR showing the reliability of "extended TPB" measurement model, the AVE suggested a lack of convergent validity on the one hand. On the other hand, discriminant validity was ascertained as square-root of AVE (.699) was well above the TPB-SMBE correlation (.512). Hence, an overall assessment of the model led to the acceptance of the model considering that AVE value slightly below the required $\geq .5$ can be accepted as long as offending estimates does not occur. All the paths shown in the initial model are significant as critical ratios were above 1.96. Therefore, the second order latent variables approach for the "extended TPB" dimension is the appropriate measurement model that supports the inclusion of SMBE variables both in a theoretical and statistical point of view. 
Figure 12: Confirmatory Model for Extended TPB Dimension/ 2 ${ }^{\text {nd }}$ Order Latent Variable Approach

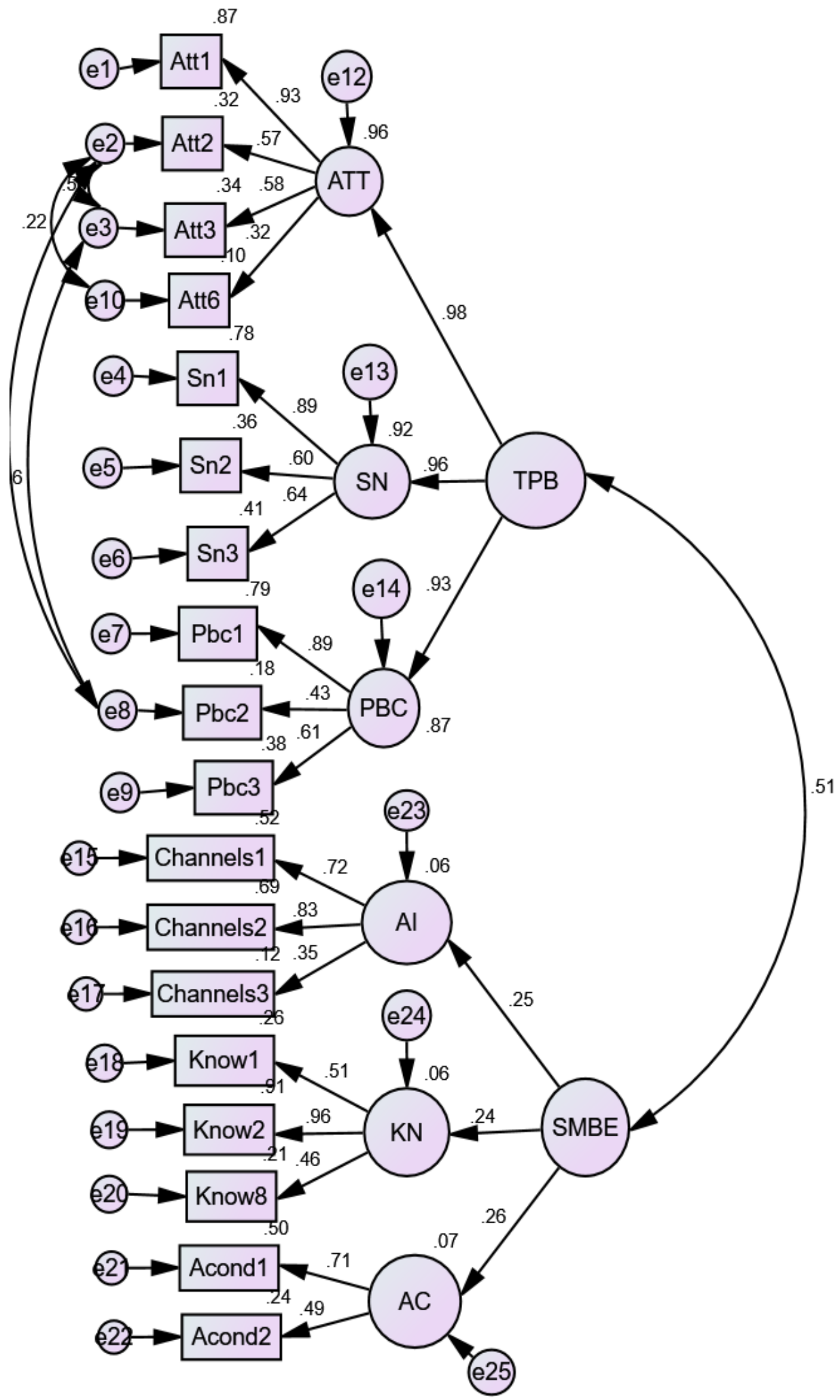

$\mathrm{CMIN}=248.54 ; \mathrm{DF}=121 ; \mathrm{CMIN} / \mathrm{DF}=2.05 ; \mathrm{p}=.00 ; \mathrm{GFI}=.96 ; \mathrm{NFI}=.94 ; \mathrm{CFI}=.97 ; \mathrm{TLI}=.96 ; \mathrm{RMSEA}=.04 ;$ $\mathrm{SRMR}=.04 ; \mathrm{AVE}=.489 ; \mathrm{CR}=.810$ 


\section{Conclusion and Recommendations}

The extension of the TPB model to SMBE variables as proposed by Ayikwa and De Jager (2017) was verified through, first and second order CFA. Prior to proceeding with CFA, an EFA was conducted and helped the study to reduce and identify factors that best explained each construct considered in the present study. ML method was applied to assess the models providing fit indices, while AVE and CR were used to determine convergent validity of the constructs and internal consistency following the CFA procedures with regard to the two approaches investigated as suggested by MacKenzie et al. (2011). The individual's assessment of the measurement models of the constructs permitted the elimination of factor components that loaded below a value of .4 rule of thumb applied except for some factors whose removal led the model to be unidentified, considering that no violation of offending estimates occurred. Both the reliability and convergent validity were accepted for all models, while rejected only for the "SMBE" dimension model. However, the first order latent variables "extended TPB" model did not show discriminant validity and therefore could not be validated paving the way for justification to explore the second-order latent variables approach. The later integrated the SMBE dimension despite the AVE and CR values being below their threshold in order to allow further processing of the study's model of interest.

The data collected were quite fit with the second order latent variables "extended TPB" model supporting the inclusion of the SMBE variables (AI, AC and KN) alongside the traditional TPB components (ATT, SN and PBC). Thus, researchers in the various behavioural fields in general, addressing the HIV/AIDS epidemic in particular, may adopt this model extending the TPB model to SMBE variables in investigating the prediction of specific sexual behaviour and their related intentions. Although this study did not validate the first order latent variables "extended TPB" model, this will not be the case all the time or in contexts other than South Africa's Gauteng Province. Therefore, the recommendation is made for further researching in different environments and the same as in this study but at a later point of time. Thus, the difficulty experienced to statistically distinguish TPB constructs from one another given their high correlations, which is not always the case, could find appropriate answers in determining if the issue lies in the wording of the items or something else. Indeed, a deeper investigation of the implied correlations of the component factors considered in the analysis revealed no value above .75. The same is also true for the poor discriminant validity and reliability showed by the measurement model for the SMBE dimension.

\section{References}

Ab Hamid, M., Sami, W. \& Mohamed Sidek, M. (2017). Discriminant Validity Assessment: Use of Fornell \& Larcker criterion versus HTMT Criterion. Journal of Physics: Conf, 1-5.

Africa, S. S. (2015). Mid-year population estimates 2015. Johannesburg: Stat SA.

Agarwal, S. \& De Araujo, P. (2012). On the association between HIV knowledge and unsafe sexual behaviour in India. International Journal of Development, 11(3), 227-234.

Ajzen, I. (1985). From Intentions to Actions: A Theory of Planned Behavior. In J. Kuhl, \& J. Beckmann, Action Control: From Cognition to Behavior. Heidelberg: Springer.

Ajzen, I. \& Fishbein, M. (1980). Understanding Attitudes and Predicting Social. Englewood-Cliffs, NJ: PrenticeHall.

Ayikwa, L. C. (2013). Preventing populations from HIV/AIDS in Kinshasa: The relevancy of empowering people through battling illiteracy. The 2013 International Conference on Business Innovation and Growth (pp. 1-9). Gaborone: University of Botswana.

Ayikwa, L. C. \& De Jager, J. W. (2017). Identifying Variables to Incorporate in an Extended TPB Model with Regards to HIV Testing in Kinshasa, DR Congo. International Journal of Environmental \& Science Education, 12(7), 1595-1603.

Ayikwa, L. \& De Jager, J. (2015). Investigating the predictive power of Social Marketing variables to control the Stigma and Discrimination towards HIV-infected persons in Kinshasa, RD Congo. In S. Goodman, G. Human, C. Mulenga, D. Priilaid, \& J. Robertson (Ed.), SAIMS (pp. 840-851). Cape Town: 27th Annual SAIMS Conference 2015.

Belkin, M. (2009). The assessment of information systems effectiveness in private and hospital pathology (Unpublished Doctorate Thesis). RMIT University.

Cohen, L., Manion, L. \& Morrison, K. (2011). Research Methods in Education (6th ed.). Abingdon: Routledge. 
Conner, M. \& Armitage, C. J. (1998). Extending the Theory of Planned Behavior: A Review and Avenues for Further Research. Journal of Applied Social Psychology, 28(15), 1429-1464.

Fishbein, M. (1967). Readings in Attitude Theory and Measurement. New York: Wiley.

Godin, G. \& Kok, G. (1996). The Theory of Planned Behavior: A Review of Its. American Journal of Health Promotion, 11, 87-98.

Hair, J., Black, W., Babin, B. \& Anderson, R. (2010). Multivariate data analysis. A global perspective (7th ed.). Upper Sadler Rever, NJ: Pearson.

Hermida, R. (2015). The problem of allowing correlated errors in structural equation modelling: concerns and considerations. Computational Methods in Social Sciences, 3(1), 5-17.

Huang, F. M. (2007). Structural Equation Modeling: Theory and Application. Taipei: Wu Nan.

Imaledo, J., Peter-Kio, O. \& Asuquo, E. (2012). Pattern of Risky Sexual Behavior and associated factors among undergraduate students of University of Port Harcourt, Rivers State, Nigeria. The Pan African Medical Journal, 12(97), 1-9.

Khonde, C. (2006). An Oral History of HIV/AIDS in the Congo. The HIV/AIDS Epidemic in Sub-Saharan Africa in a Historical Perspective.

Kiriakidis, S. (2015). Theory of Planned Behaviour: the Intention-Behaviour Relationship and the Perceived Behavioural Control (PBC) Relationship with Intention and Behaviour. International Journal of Strategic Innovative Marketing, 03, 40-51.

Kline, R. (2010). Principles and practice of structural equation modelling (3rd ed.). New York: Guilford Press.

Lin, S. (2013). Measuring Marketing Constructs: A Comparison of Three Measurement Theories (Unpublished master's thesis). Bergen, Fall: Norwegian School of Economics.

Luboobi, L. S. \& Mugisha, J. Y. (2005). HIV/AIDS Epidemic in Africa: Trends and Challenges. Nota di Lavoro, 103.

MacKenzie, S., Podsakoff, P. \& Podsakoff, N. (2011, June). Construct Measurement and Validation procedures in MIS and Behavioral Research: Integrating new and existing techniques. MIS Quarterly, 35(2), A1A5.

Mathews, C., Aarø, L., Flisher, A., Mukoma, W., Wubs, A. \& Schaalma, H. (2009). Predictors of early first sexual intercourse among adolescents in Cape Town, South Africa. Health Education Research, 24(1), 1-10.

Mayhew, M. J., Hubbard, S. M., Finelli, C. J. \& Harding, T. S. (2009). Using Structural Equation Modeling to Validate the Theory of Planned Behavior as a Model for Predicting Student Cheating. The Review of Higher Education, 32(4), 441-468.

Nunnally, C. \& Bernstein, I. (2010). Psychometric theory. New York: McGraw-Hill.

Sacolo, H., Chung, M. H., Chu, H., Liao, Y. M., Chen, C. H., Ou, K. L. \& Chou, K. R. (2013, July). High-Risk Sexual Behaviors for HIV among the In-School Youth in Swaziland: A Structural Equation Modeling approach. PLOS ONE, 8(7), e67289.

Schumacker, R. \& Lomax, R. (2012). A Beginner's Guide to Structural Equation Modeling (3rd ed.). New York: Routledge.

Selikow, T. A. (2004). We have our own special language, Sexuality and HIV/AIDS: A case study of youth in an urban township in South Africa. African Health Sciences, 4(2), 102-108.

Shyu, C. H., Li, Y. L. \& Tang, Y. (2013, August). Applying Confirmatory Factor Analysis on the Measure for Restaurant Over-service. The Journal of International Management Studies, 8(2), 10-16.

Tameru, B., Gerbi, G., Nganwa, D., Bogale, A., Robnett, V. \& Habtemariam, T. (2012). The Association between Interrelationships and Linkages of Knowledge about HIV/AIDS and its Related Risky Behaviors in People Living with HIV/AIDS. J AIDS Clinic Res, S7(002), 2-7.

Tao, C. C. \& Fan, C. C. (2017). A Modified Decomposed Theory of Planned Behaviour Model to Analyze User Intention towards Distance-Based Electronic Toll Collection Services. Promet - Traffic \& Transportation, 29(1), 85-97.

Ugwu, O. M. (2012). Knowledge and Attitude of Secondary School Students towards Sexually Transmitted Diseases in NSUKKA Education Zone (Unpublished Master Thesis). Nsukka: Univerisity of Nigeria. 